Article

\title{
Production of Fungal Biomass for Feed, Fatty Acids, and Glycerol by Aspergillus oryzae from Fat-Rich Dairy Substrates
}

\author{
Amir Mahboubi ${ }^{1,2, *} \mathbb{( D}^{\mathbb{D}}$, Jorge A. Ferreira ${ }^{1}$, Mohammad J. Taherzadeh ${ }^{1}$ \\ and Patrik R. Lennartsson ${ }^{1}$ \\ 1 Swedish Centre for Resource Recovery, University of Borås, 50190 Borås, Sweden; \\ Jorge.Ferreira@hb.se (J.A.F.); mohammad.taherzadeh@hb.se (M.J.T.); Patrik.Lennartsson@hb.se (P.R.L.) \\ 2 Flemish Institute for Technological Research, VITO NV, Boeretang 200, B-2400 Mol, Belgium \\ * Correspondence: amir.mahboubi_soufiani@hb.se; Tel.: +46-33-4354612; Fax: +46-33-4354003
}

Received: 31 August 2017; Accepted: 19 September 2017; Published: 22 September 2017

\begin{abstract}
Dairy waste is a complex mixture of nutrients requiring an integrated strategy for valorization into various products. The present work adds insights into the conversion of fat-rich dairy products into biomass, glycerol, and fatty acids via submerged cultivation with edible filamentous fungi. The $\mathrm{pH}$ influenced fat degradation, where Aspergillus oryzae lipase was more active at neutral than acidic $\mathrm{pH}(17 \mathrm{~g} / \mathrm{L}$ vs. $0.5 \mathrm{~g} / \mathrm{L}$ of released glycerol); the same trend was found during cultivation in crème fraiche (12 g/L vs. $1.7 \mathrm{~g} / \mathrm{L}$ of released glycerol). In addition to glycerol, as a result of fat degradation, up to 3.6 and $4.5 \mathrm{~g} / \mathrm{L}$ of myristic and palmitic acid, respectively, were released during A. oryzae growth in cream. The fungus was also able to grow in media containing $16 \mathrm{~g} / \mathrm{L}$ of lactic acid, a common contaminant of dairy waste, being beneficial to naturally increase the initial acidic $\mathrm{pH}$ and trigger fat degradation. Considering that lactose consumption is suppressed in fat-rich media, a two-stage cultivation for conversion of dairy waste is also proposed in this work. Such an approach would provide biomass for possibly feed or human consumption, fatty acids, and an effluent of low organic matter tackling environmental and social problems associated with the dairy sector.
\end{abstract}

Keywords: biomass for feed; dairy waste; edible filamentous fungi; fatty acids; glycerol

\section{Introduction}

Considering the important role of dairy products and related industries in the daily life and well-being of an increasing human population, it is also of environmental, social, and economic importance to have promising methods to treat the dairy waste generated. Therefore, efficient waste management routes need to be developed to cope with increasing amounts of dairy waste. One of those strategies includes biological treatment with edible filamentous fungi whose diversified enzymatic machinery enables the hydrolysis of complex nutrients for further assimilation and conversion to various value-added products [1,2]. Dairy substrates are potential sources of lactose, protein, and fat, where the latter varies between 3\% in low-fat dairy substrates (e.g., milk) and $40 \%-50 \%$ in fat-rich substrates (e.g., cream and crème fraiche) [3]. Therefore, bringing together the metabolic diversity of filamentous fungi and the complex composition of dairy waste, there is a high potential for building biorefineries worldwide where dairy waste is biologically converted to various value-added products. This can have important environmental and social implications considering the amount of dairy waste generated, its environmental pollution potential, and biorefinery-related job creation.

Edible filamentous fungi such as Aspergillus oryzae and Neurospora intermedia have previously been investigated for valorization of dairy waste products including cheese-whey, milk, yoghurt, cream, and fermented cream (crème fraiche) and management routes and their output potential have been 
proposed [3]. Special emphasis was placed on lactose assimilation, production of biomass that can be used for feed applications, and fat degradation with concomitant release of glycerol. N. intermedia has been used for production of the Indonesian food oncom; however, it is a rather unexplored fungus from a biotechnological point of view [2]. A. oryzae, found worldwide but of higher incidence in tropical environments [4], is one of the most studied fungi at the industrial level where it contributes to the production of several products including a variety of organic acids and enzymes [5]. In addition, A. oryzae is traditionally used for production of various human food products (e.g., miso) and beverages (e.g., sake) in China and other East Asian countries [6]. Interestingly, A. oryzae was found to change its metabolic preference from lactose assimilation in low-fat dairy waste to fat degradation in high-fat dairy waste [3]. Therefore, fatty acids and glycerol, together with fungal biomass, would have a crucial role in the economic feasibility of bioconversion processes centered on dairy waste. Thus, further insights are needed regarding optimization of fat degradation by A. oryzae in dairy waste together with the characterization of the fatty acids released. Nearly $60 \%$ of milk fatty acids are saturated, where palmitic, stearic, and myristic acids dominate; polyunsaturated fatty acids such as linoleic acid only account for about $4 \%$. Functional food monounsaturated fatty acids are also present in milk, for instance, oleic acid represents about $25 \%$ of milk fatty acid content [7-9].

The present study focuses on $A$. oryzae fat degradation capabilities in fat-rich substrates, namely cream and crème fraiche (pasteurized cream soured using lactic acid producing bacteria [10]). Special emphasis was given to the effect of $\mathrm{pH}$ and lactic acid on fat degradation and concomitant release of glycerol and fatty acids whose characterization was carried out. Bringing together all available insights on valorization of dairy substrates with edible filamentous fungi, an integrated bioconversion system for management of dairy waste is proposed.

\section{Materials and Methods}

\subsection{Microorganism}

Aspergillus oryzae var. oryzae CBS 819.72 (Centraalbureau voor Schimmelcultures, Utrecht, The Netherlands) was used throughout this study. The ascomycete was maintained in potato dextrose agar (PDA) plates containing $20 \mathrm{~g} / \mathrm{L}$ glucose, $15 \mathrm{~g} / \mathrm{L}$ agar, and $4 \mathrm{~g} / \mathrm{L}$ potato extract. New plates were prepared on a two-week basis via inoculation with $100 \mu \mathrm{L}$ of spore solution obtained by flooding a pre-grown plate with $20 \mathrm{~mL}$ sterile distilled water; disposable spreaders were used to bring the spores into solution and to spread the spore solution onto new plates. The inoculated plates were incubated at $30^{\circ} \mathrm{C}$ for $3-5$ days followed by storage at $4{ }^{\circ} \mathrm{C}$ until use for cultivation.

\subsection{Dairy Substrates}

Fresh cream (grädde, Falköping Mejeri, Falköping, Sweden) and crème fraiche (sour cream, ICA, Borås, Sweden) were purchased locally. Cream contained $48 \%(w / w)$ total solids composed of $40 \%$ fat, $3 \%$ carbohydrates, and 2\% protein (Falköping Mejeri, Falköping, Sweden); crème fraiche contained $40 \%(w / w)$ solids composed of $34 \%$ fat, $3 \%$ carbohydrates, and $2 \%$ protein (ICA, Borås, Sweden). Both substrates were sterilized at $121^{\circ} \mathrm{C}$ for $20 \mathrm{~min}$ followed by storage at $4{ }^{\circ} \mathrm{C}$ until use for cultivation. For cultivations in separated solid and liquid fractions of cream, it was centrifuged at $3000 \times g$ for $5 \mathrm{~min}$ and the solid fractions were diluted to the starting volume with distilled water. Both fractions were sterilized in $250 \mathrm{~mL}$ Erlenmeyer flasks containing $100 \mathrm{~mL}$ of medium at $121^{\circ} \mathrm{C}$ for $20 \mathrm{~min}$.

\subsection{Cultivations}

All cultivations were carried out using $250 \mathrm{~mL}$ Erlenmeyer flasks containing $100 \mathrm{~mL}$ of medium. The flasks were inoculated with $20 \mathrm{~mL} / \mathrm{L}$ of solution containing $1.8 \times 10^{7}$ spores/L and incubated in a water bath shaking at $125 \mathrm{rpm}$ at $35{ }^{\circ} \mathrm{C}$ for 4-6 days. Cultivations in non-sterile cream were carried out by transferring, under sterilized conditions, $100 \mathrm{~mL}$ cream into pre-sterilized empty $250 \mathrm{~mL}$ Erlenmeyer flasks. Cultivations in semi-synthetic medium were carried out as above using lactic 
acid $(20 \mathrm{~g} / \mathrm{L})$ and glycerol $(30 \mathrm{~g} / \mathrm{L})$ as single carbon sources together with salts and with or without supplementation of yeast extract according to Sues et al. [11]. Samples were withdrawn under sterile conditions during cultivation at regular intervals where the liquid fractions after centrifugation at $3000 \times g$ for $5 \mathrm{~min}$ were stored at $-20^{\circ} \mathrm{C}$ for further analyses. At the end of the cultivation, the biomass was harvested using a sieve $\left(1 \mathrm{~mm}^{2}\right.$ pore size) and washed thoroughly with distilled water to remove extracellular medium residuals. All cultivations were carried out in duplicate.

\subsection{Analyses}

The harvested biomass was dried to constant weight in an oven at $70{ }^{\circ} \mathrm{C}$ and biomass yields are reported as $\mathrm{g}$ of biomass per liter of the dairy substrate.

Profiles of glycerol, lactic acid, lactose, glucose, other sugars, ethanol, and fatty acids were constructed based on high-performance liquid chromatography (HPLC) analysis. A hydrogen-ion based ion-exchange column (Aminex HPX-87H, Bio-Rad, Hercules, CA, USA) at $60{ }^{\circ} \mathrm{C}$ and $0.6 \mathrm{~mL} / \mathrm{min}$ of $5 \mathrm{mM} \mathrm{H}_{2} \mathrm{SO}_{4}$ was used for analysis of all components except fatty acids. Myristic, palmitic, oleic, and stearic acids were analyzed using a C18 XBridge BEH Phenyl column (Waters Corporation, Milford, MA, USA) at $45{ }^{\circ} \mathrm{C}$ and $0.6 \mathrm{~mL} / \mathrm{min}$ of acetonitrile-water (85:15). An ultraviolet (UV) absorbance detector (Waters 2487, Waters Corporation, Milford, MA, USA), operating at $210 \mathrm{~nm}$ wavelength, was used in series with a refractive index (RI) detector (Waters 2414).

Derivatization of the fatty acids in the experimental samples and respective standard mixtures was carried out as follows: $0.5 \mathrm{~mL}$ of the sample was dried under nitrogen stream followed by the addition of $0.5 \mathrm{~mL}$ of $20 \mathrm{mg}$ bromoacetophenone/mL acetone and $0.5 \mathrm{~mL}$ of $25 \mathrm{mg}$ triethylamine $/ \mathrm{mL}$ acetone. The mixture was vortexed and then placed in a heating block at $100{ }^{\circ} \mathrm{C}$ for $15 \mathrm{~min}$ with the tubes open. After cooling, $0.75 \mathrm{~mL}$ of $10 \mathrm{mg}$ acetic acid $/ \mathrm{mL}$ acetone were added, heated at $100{ }^{\circ} \mathrm{C}$ for $5 \mathrm{~min}$, and then dried under nitrogen stream. The volume of the samples was adjusted to $1 \mathrm{~mL}$ with acetonitrile-water (85:15), vortexed, centrifuged, and the supernatant was used for HPLC analysis.

The nitrogen content of solid and liquid fractions of cream was analyzed using the Kjeldahl method according to [3].

\subsection{Statistical Analysis}

All experiments performed in this study have been carried out in duplicate and the average values plus the error bars representing two standard deviations are illustrated on the graphs. The data acquired were statistically analyzed using MINITAB ${ }^{\circledR} 17$ (Minitab Ltd., Coventry, UK). A general linear model with a confidence interval of $95 \%$ was applied for the analysis of variance (ANOVA). To have a better understanding of the extent of differences between results obtained, pairwise comparisons according to Tukey's test were performed.

\section{Results and Discussion}

Generally, dairy waste can be divided into fat-rich and low-fat substrates, where lactose contributes a great fraction of the chemical oxygen demand in the latter [12]. Understanding lactose consumption by A. oryzae and N. intermedia has previously been a subject of research [3]. Nonetheless, further investigation on fat degradation by edible filamentous fungi is needed in order to build a process that will lead to full conversion of the nutrients present in dairy waste to various value-added products. The present study focused on the influence of $\mathrm{pH}$ on fat degradation in order to give further insights regarding the optimal conditions for lipase production by A. oryzae, the lactic acid concentration as a result of bacterial growth, and the need for dairy waste sterilization before fungal cultivation. Furthermore, a characterization of the fatty acids released during fat degradation is presented together with a proposal for an integrated bioconversion process where all dairy waste is converted to various value-added products using edible filamentous fungi. 


\subsection{The Effect of $\mathrm{pH}$ on Fat Degradation by A. oryzae}

Species belonging to the Aspergillus genus can grow at a wide range of $\mathrm{pH}$ values which together with temperature among other parameters, can influence enzyme production and activity [13]. Therefore, A. oryzae was grown in cream with $\mathrm{pH}$ initially adjusted from 4.3 to 7 . As can be observed in Figure 1, $\mathrm{pH}$ played a crucial role on fat degradation, where the amount of glycerol released (as a result of fat degradation) increased from $0.5 \mathrm{~g} / \mathrm{L}$ at acidic $\mathrm{pH}$ to $17.2 \mathrm{~g} / \mathrm{L}$ at neutral $\mathrm{pH}$. Differences in glycerol concentration were more evident up to $\mathrm{pH} 6$ than within the $\mathrm{pH}$ interval 6-7 (Figure 1). Thus, at the examined conditions, production of lipase by $A$. oryzae was favored at neutral $\mathrm{pH}$, which is in agreement with previous studies [14]. Neutral $\mathrm{pH}$ has also been observed to induce the highest lipase activity by A. flavus, while a $\mathrm{pH}$ of 6 was reported to induce the highest lipase activity in A. niger [15]. Therefore, $\mathrm{pH}$ values leading to the highest lipase activities vary naturally among Aspergillus species. The present research adds further insights into the biological conversion of dairy substrates by $A$. oryzae, since its lactase was found to have the highest activity within the $\mathrm{pH}$ range of 4-6 [3]. Furthermore, a temperature range of $30-37^{\circ} \mathrm{C}$ is reported to induce maximal lipase activity by Aspergillus species [13-15]. Since the $\mathrm{pH}$ had not been kept constant during cultivation, a further experiment was carried out to establish a relationship between $\mathrm{pH}$ value and biomass production over time (Figure 2). The initial $\mathrm{pH}$ of cream after sterilization was $6.18 \pm 0.11$ and it decreased continuously to $5.36 \pm 0.02$ after $94 \mathrm{~h}$ and remained unchanged until the end of cultivation. As can be seen in Figure 2, as the $\mathrm{pH}$ reached 5.3, the biomass weight profile reached a plateau at $\sim 5 \mathrm{~g} / \mathrm{L}$. This implies that low $\mathrm{pH}$ interferes with the growth of $A$. oryzae in cream media. It remains to be revealed how the decreasing $\mathrm{pH}$ influences the degradation of fat with consequent release of glycerol at longer cultivation times since a plateau has not been reached (Figure 1).

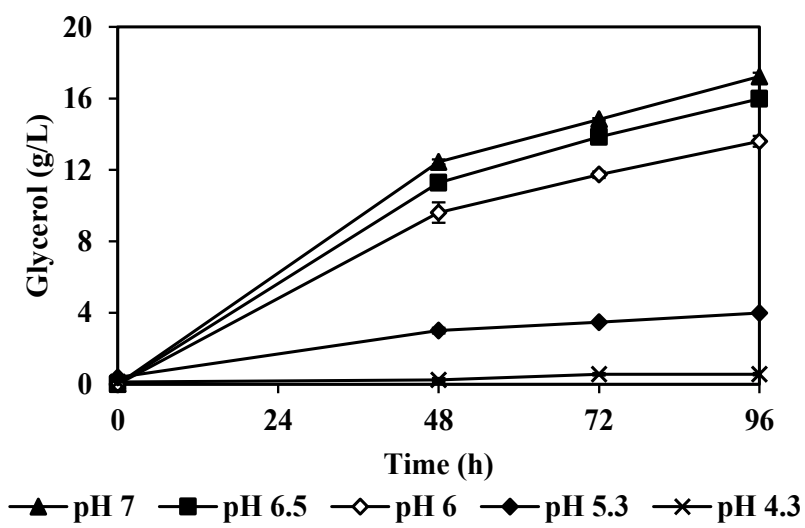

Figure 1. The effect of $\mathrm{pH}$ on fat degradation and glycerol release by A. oryzae in cream.

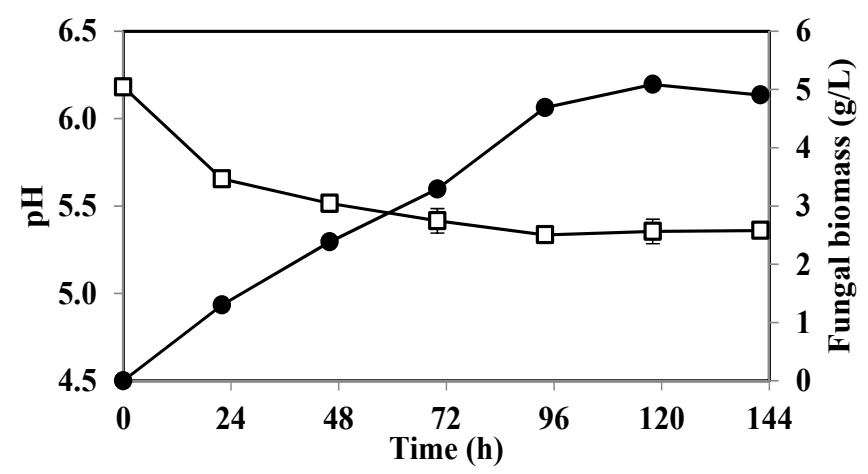

Figure 2. The trend of change in $\mathrm{pH}(\square)$ and biomass $(\bullet)$ concentration in the medium containing cream and A. oryzae. 


\subsection{Fatty Acids Released by A. oryzae Fat Degradation}

The contents of the fatty acids palmitic, myristic, stearic, and oleic acids were followed during cultivation in cream initially adjusted to $\mathrm{pH}$ 6. In complete agreement with the overtime release of glycerol, an increase in the release of the analyzed fatty acids was observed during cultivation (Figure 3). The final concentration of palmitic $(4.56 \pm 0.44 \mathrm{~g} / \mathrm{L})$ and myristic $(3.68 \pm 0.08 \mathrm{~g} / \mathrm{L})$ acids were considerably higher than that of stearic and oleic acids (less than $1 \mathrm{~g} / \mathrm{L}$ of each). This difference in the release of fatty acids may be due to the type and activity of the lipase produced by A. oryzae [14,16]. Lipases are selective on the substrate; therefore, the final product depends on whether the initial substrates are more concentrated in tri-, di-, or mono-glycerides [17]. In addition, lipases are regioselective, with preference to act depending on the positioning of the fatty acids on the glycerol backbone. Svendsen [17] has reported that fungal lipase preferably acts on sn1 and sn3 positions on the triglyceride backbone. It is noteworthy that in milk fat triglyceride backbone, short chain fatty acids usually take sn 3 and positions sn1 and sn2 are occupied by longer chain fatty acids [18].

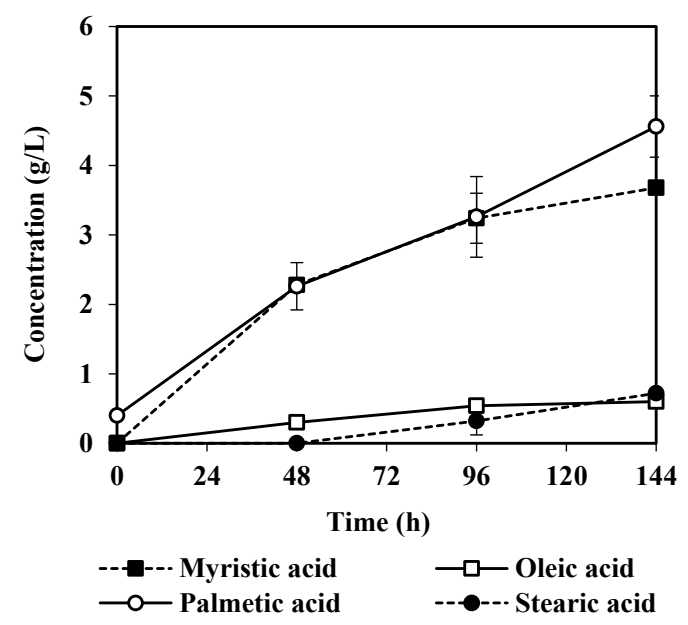

Figure 3. Changes in the concentration of main fatty acids in cream during the cultivation of A. oryzae.

However, when taking the lipid composition into account the detected glycerol concentration was more than 10 times higher than that of fatty acids. Thus, most likely the fungus is either metabolizing or storing the released fatty acids.

As reported by [3], in contradiction to low-fat dairy media, in cultivation of $A$. oryzae in fat-rich dairy cream medium there is a metabolic shift from lactose utilization to fat degradation. However, surprisingly, there seemed to be both very poor lactose consumption (lactose concentration remained constant throughout the cultivation [3]) and fat degradation in the case of crème fraiche, although both cream ( $40 \%$ fat) and crème fraiche (38\% fat) are fat-rich dairy media. This activity hindrance may be due to the presence of about $11 \mathrm{~g} / \mathrm{L}$ of lactic acid in the as-received crème fraiche that drops the initial $\mathrm{pH}$ to about 4.3, which according to previously obtained results is an unfavorable $\mathrm{pH}$ for fungal lipase activity. Therefore, the $\mathrm{pH}$ value effect on fat degradation was also investigated using crème fraiche as substrate (Figure 4). Expectedly, the increase in $\mathrm{pH}$ towards neutral range boosted fat degradation where glycerol release of up to $12 \mathrm{~g} / \mathrm{L}$ at $\mathrm{pH} 6.5$ was obtained. 


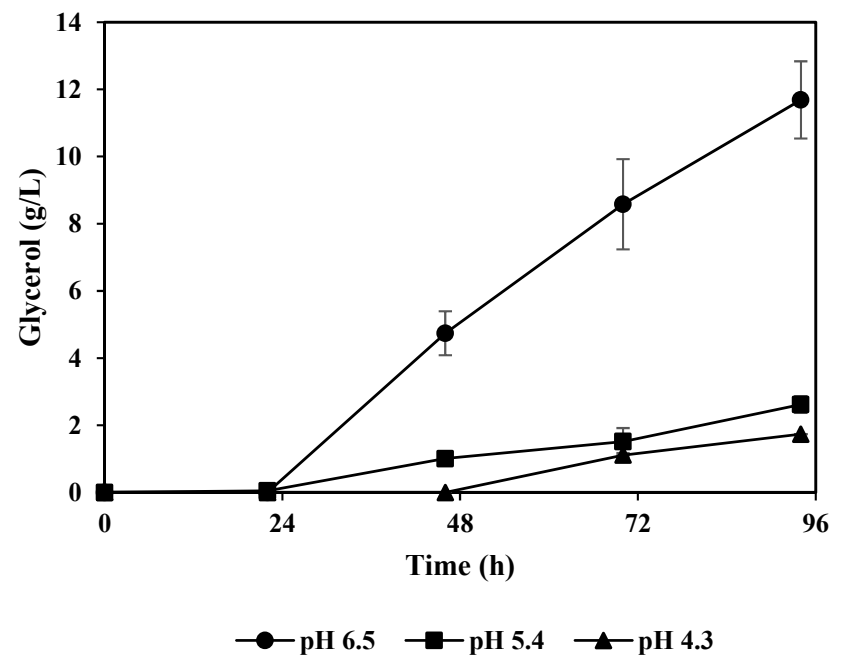

Figure 4. Glycerol yield in $\mathrm{pH}$ adjusted crème fraiche medium inoculated by A. oryzae.

\subsection{Lactic Acid and Glycerol Consumption by A. oryzae}

In non-sterile cream, as in the case of cream waste, the present bacterial consortium, mainly constituted by lactic acid bacteria, can grow on the lactose substrate, producing lactic acid as the main product. Lactic acid is partly behind the sour taste and rancid smell of expired dairy products. The lactic acid content of the medium as reported in the literature can act as fungicide $[19,20]$, thus hindering the favorable metabolic activity of the fungal strain. On the other hand, as an increase in the concentration of lactic acid in the cultivation medium results in a drop of the $\mathrm{pH}$, it may alter the trend of fat degradation by $A$. oryzae. Therefore, to study the effect of concomitant presence of $A$. oryzae and lactic acid bacteria in cream, the ability of $A$. oryzae to consume lactic acid as the sole carbon source was tested in semi-synthetic medium (Figure 5). Results from cultivation of $A$. oryzae in non-sterile cream can be found in a previous work [3]. As it can be observed, in the presence of a nitrogen source and $16 \mathrm{~g} / \mathrm{L}$ of lactic acid the fungus was able to consume $37.5 \%$ of the acid within $96 \mathrm{~h}$ of cultivation. The degradation of lactic acid by different filamentous fungi including A. oryzae has been previously reported $[3,21,22]$. These results are promising when it comes to long cultivation periods, since if a stepwise process is applied, $A$. oryzae initially consumes lactic acid, and subsequently as the $\mathrm{pH}$ rises fat degradation will become dominant. This becomes even more critical when it comes to dairy waste, which contains considerable amounts of lactic acid bacteria that are constantly consuming lactose and producing lactic acid. In the presence of both the fungus and lactic acid bacteria, there seems to be no interference or interruption in the metabolic activity up to a certain initial lactic acid concentration, however, further metabolic behavior in this system is closely dependent on whether the lactic acid bacteria or fungus takes over the culture later in the cultivation process. This has also been proven in the work of de Vrese et al. [23]. Moreover, as A. oryzae has been reported to be a poor lactose consumer in fat-rich dairy media [3], parallel production of lactic acid by lactic acid bacteria that can be consumed by the fungus as a secondary substrate can be of interest from a process development point of view.

With the intensification of biodiesel production as a fuel replacement to diesel, the worldwide production of glycerol has concomitantly increased. Due to its surplus, the price of glycerol will have the tendency to decrease. Therefore, instead of considering glycerol as a final product, it is also considered in this study as a potential carbon source for A. oryzae. The fungus was grown in a semi-synthetic medium containing about $27 \mathrm{~g} / \mathrm{L}$ glycerol as the sole carbon source together with magnesium, calcium, potassium, and ammonium salts, where the effect of absence or presence of yeast extract was investigated. As presented in Figure 5, when the medium was supplemented with yeast extract, $95 \%$ of the initial glycerol in the medium was consumed within $96 \mathrm{~h}$ of cultivation, while only $10 \%$ of the initial glycerol was consumed when yeast extract was absent. The results are in compliance 
with $7.09 \pm 0.78$ and $0.61 \pm 0.13 \mathrm{~g} / \mathrm{L}$ of biomass produced in cultivation media supplemented or not with yeast extract, respectively.

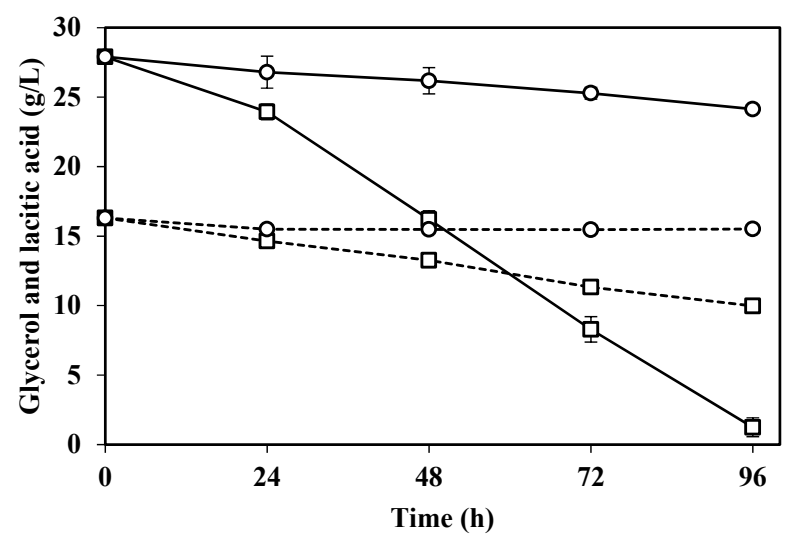

Figure 5. Utilization of lactic acid (dashed line) and glycerol (solid line) by A. oryzae in mediums supplemented with salt mixture $(\bigcirc)$ or salt and yeast extract $(\square)$.

\subsection{Cultivation of A. oryzae in Different Fractions of Cream}

Since the metabolic activity of $A$. oryzae alters in fat-rich dairy media, where lactose consumption is suppressed and lipid degradation encouraged, the ascomycete was cultivated in separated liquid and solid fractions of cream [3]. The results of cultivation of $A$. oryzae in cream fat and fat-free cream fractions are presented in Figure 6. The activity of the fungal strain in the fat-free portion of cream towards lactose utilization even at low and favorable $\mathrm{pH} 4.3$ for $A$. oryzae lactase activity was low. Only $17 \%, 5 \%$, and $5 \%$ of the initial lactose was assimilated by $A$. oryzae at $\mathrm{pH} 4.3,5.3$, and 6.3 by the end of cultivation, respectively (Figure $6 \mathrm{~A}$ ). Taking into account the $\mathrm{C} / \mathrm{N}$ ratio of 4 obtained by the Kjeldahl analysis, the poor lactose consumption should not be related to lack of nitrogen but to other nutrients that remained in the solid fraction after centrifugation. According to statistical analysis of the results, lactose consumption at $\mathrm{pH} 4.3$ was significantly higher $(p$ value $=0.001)$ than that at 5.3 and 6.3, which relatively had no significant difference ( $p$ value $=0.126$ ). These differences were also corroborated by the biomass yields obtained of $9.96 \pm 1.90,5.38 \pm 0.42$, and $2.48 \pm 0.56 \mathrm{~g} / \mathrm{L}$ after cultivation at $\mathrm{pH} 4.3,5.3$, and 6.3 , respectively.

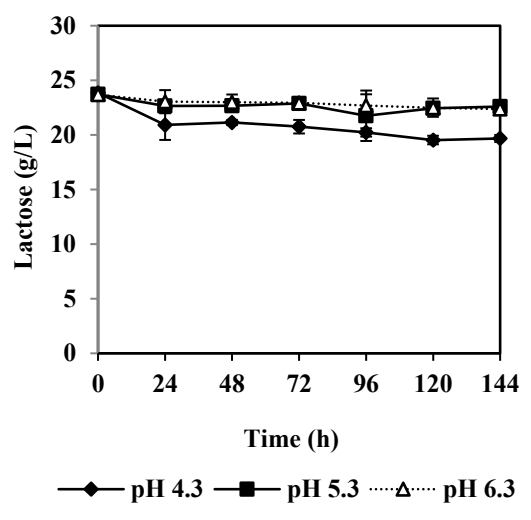

A

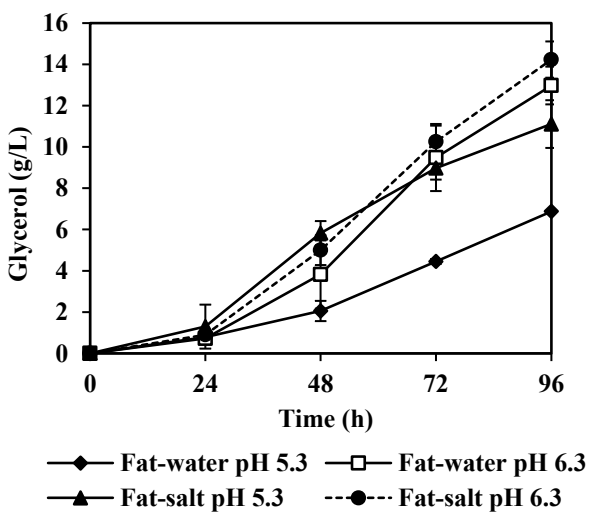

B

Figure 6. The changes in the (A) lactose content of the fat-free cream fraction inoculated with A. oryzae at different $\mathrm{pH}$ values and (B) glycerol concentration of the cream fat fraction inoculated with $A$. oryzae at different $\mathrm{pH}$ values and medium compositions. 
Regarding the cultivation of A. oryzae in the fat-rich fraction of cream (Figure 6B) diluted with water or salt solution at different $\mathrm{pH}$ values, it can be observed that at $\mathrm{pH} 5.3$ when the medium was provided with adequate salt mixture (including a nitrogen source in the form of ammonium), the concentration of glycerol released $(11.11 \pm 1.15 \mathrm{~g} / \mathrm{L})$ was significantly $(p$ value $=0.005)$ higher than that when the cream fat was only diluted with water $(6.88 \pm 0.04 \mathrm{~g} / \mathrm{L})$. In comparison to salt supplemented medium at pH 5.3, no significant differences were observed regarding glycerol concentrations at $\mathrm{pH} 6.3$ in cultures with water $(12.98 \pm 0.91 \mathrm{~g} / \mathrm{L})$ or salt solution $(14.23 \pm 0.88 \mathrm{~g} / \mathrm{L})$. Although the fungal biomass harvested from the salt supplemented cultivation medium at $\mathrm{pH} 6.3$ $(2.17 \pm 0.12 \mathrm{~g} / \mathrm{L})$ was the highest of the four preparations, the intercellular lipid accumulated and released during oven drying of $A$. oryzae biomass [3] interferes with exact biomass measurements.

\subsection{Proposed Integrated Bioconversion Unit of Dairy Substrates to Various Value-Added Products}

The present study adds further insights into process requirements for full conversion of the nutrients in dairy waste to value-added products. A. oryzae has previously been found to change its metabolic preference, where fat degradation is preferred over lactose assimilation in fat-rich media and vice-versa. Such an expressive metabolic shift (based on the amount of glycerol released) has not been found for Neurospora intermedia, where lactose consumption assumes the highest relevance independently of the medium used [3]. Such performance differences call for an integrated process where both fungi are used in series (Figure 7) within a biorefinery-based concept for valorization of dairy waste. Overall, fat-rich dairy waste can be diluted with sour milk, cheese whey, or any other low-fat waste material to a fat content within $10-40 \%$ and used for cultivation with $A$. oryzae in a first bioreactor under aerobic conditions. During this first stage, $A$. oryzae will degrade fat and likely proteins, releasing fatty acids and glycerol. The medium is filtrated into a second aerobic bioreactor where $N$. intermedia receives a stream rich in lactose, lactic acid, glycerol, and fatty acids and produces biomass that can be easily separated by sieving and sold possibly for animal feed or human food applications. Despite the edible character of $A$. oryzae, further studies need to be performed within the overall process development in order to evaluate its suitability for animal feed or human consumption, since the growth substrate will be very heterogeneous. Depending on the conditions applied, the final liquid fraction should be very low in organic matter, which eases water recycling, and with fatty acids that can also have feed or human food applications. Further studies are needed in order to investigate the process performance at reactor scale and the influence of, for example, oxygen. Altogether, filamentous fungi can be used to tackle a social and environmental problem of increasing amounts of dairy waste, via building an integrated bioconversion process that can supply several different products into various industrial sectors.

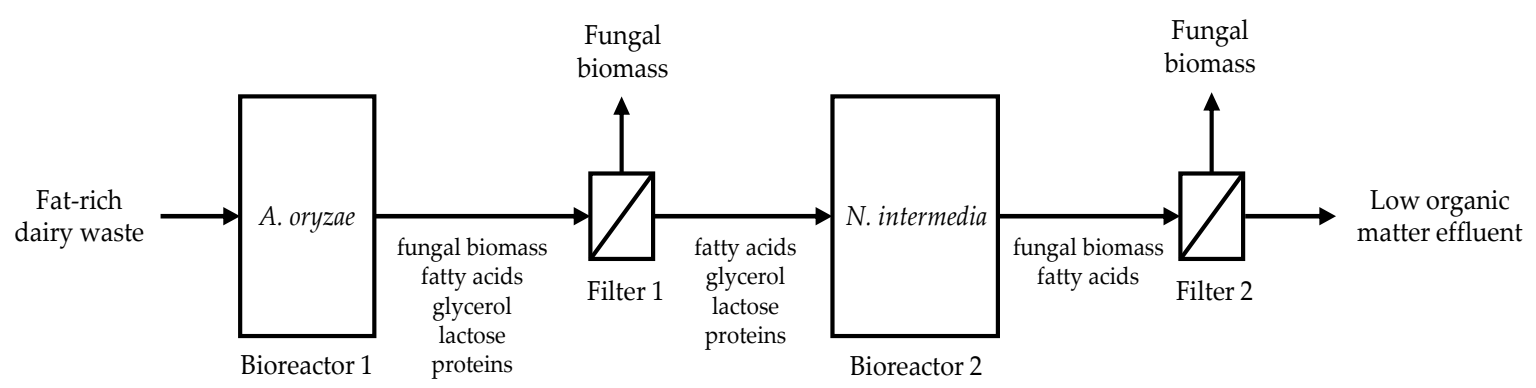

Figure 7. Schematic of the proposed integrated bioconversion process stages for fungal bioconversion of fat-rich dairy substrates to value-added products.

\section{Conclusions}

The present study adds important insights on the valorization of fat-rich substrates. The $\mathrm{pH}$ was found to have a critical effect on fat degradation by $A$. oryzae during growth in cream and 
fermented crème (crème fraiche). The concentration of released glycerol was 0.5 and $17 \mathrm{~g} / \mathrm{L}$ during fungal cultivation in cream at acidic and neutral $\mathrm{pH}$, respectively; a range of 1.7-12 g/L was observed when changing from acidic to neutral $\mathrm{pH}$ in crème fraiche. It was also found that a high concentration of lactic acid, due to contamination, will not have a negative impact on fat degradation by A. oryzae. Due to suppression of lactose consumption in fat-rich media, a two-stage cultivation using A. oryzae as a fat degrader and Neurospora intermedia as a lactose consumer is hypothesized to be the right strategy to build a biorefinery resembling process around dairy waste for supply of biomass for feed or human consumption, fatty acids, and low organic matter-containing effluent of easy disposal, or for easy water recycling.

Acknowledgments: This work was financially supported by Swedish Research Council Formas.

Author Contributions: Amir Mahboubi carried out the experimental work and part of the writing; Jorge A. Ferreira was responsible for part of the writing and contributed to the discussion during the research work; Mohammad J. Taherzadeh and Patrik R. Lennartsson developed the idea and contributed to the discussion during the research and the revision of the manuscript.

Conflicts of Interest: The authors declare no conflicts of interest.

\section{References}

1. Ferreira, J.A.; Lennartsson, P.R.; Edebo, L.; Taherzadeh, M.J. Zygomycetes-based biorefinery: Present status and future prospects. Bioresour. Technol. 2013, 135, 523-532. [CrossRef] [PubMed]

2. Ferreira, J.A.; Mahboubi, A.; Lennartsson, P.R.; Taherzadeh, M.J. Waste biorefineries using filamentous ascomycetes fungi: Present status and future prospects. Bioresour. Technol. 2016, 215, 334-345. [CrossRef] [PubMed]

3. Mahboubi, A.; Ferreira, J.A.; Taherzadeh, M.J.; Lennartsson, P.R. Value-added products from dairy waste using edible fungi. Waste Manag. 2017, 59, 518-525. [CrossRef] [PubMed]

4. Barbesgaard, P.; Heldt-Hansen, H.P.; Diderichsen, B. On the safety of Aspergillus oryzae: A review. Appl. Microbiol. Biotechnol. 1992, 36, 569-572. [CrossRef] [PubMed]

5. Gibbs, P.A. Growth of filamentous fungi in submerged culture: Problems and possible solutions. Crit. Rev. Biotechnol. 2000, 20, 17-48. [CrossRef] [PubMed]

6. Bentley, R. From miso, sake and shoyu to cosmetics: A century of science for kojic acid. Nat. Prod. Rep. 2006, 23, 1046-1062. [CrossRef] [PubMed]

7. Bauman, D.E.; Lock, A. Milk fatty acid composition: Challenges and opportunities related to human health. In Proceedings of the XXVI World Buiatrics Congress, Santiago, Chile, 14-18 November 2010; Cornell University: New York, NY, USA, 2010; pp. 278-289.

8. Nettleton, J. Introduction to Fatty Acids. In Omega-3 Fatty Acids and Health; Springer: Berlin, Germany, 1995; 63p.

9. Yilmaz-Ersan, L. Fatty acid composition of cream fermented by probiotic bacteria. Mljekarstvo 2013, 63, 132-139.

10. Meunier-Goddik, L. Sour Cream and Creme Fraiche. In Handbook of Food and Beverage Fermentation Technology; CRC Press: Boca Raton, FL, USA, 2004.

11. Sues, A.; Millati, R.; Edebo, L.; Taherzadeh, M.J. Ethanol production from hexoses, pentoses, and dilute-acid hydrolyzate by Mucor indicus. FEMS Yeast Res. 2005, 5, 669-676. [CrossRef] [PubMed]

12. Guimarães, P.M.R.; Teixeira, J.A.; Domingues, L. Fermentation of lactose to bio-ethanol by yeasts as part of integrated solutions for the valorisation of cheese whey. Biotechnol. Adv. 2010, 28, 375-384. [CrossRef] [PubMed]

13. Xia, J.L.; Huang, B.; Nie, Z.Y.; Wang, W. Production and characterization of alkaline extracellular lipase from newly isolated strain Aspergillus awamori HB-03. J. Cent. South Univ. Technol. 2011, 18, 1425-1433. [CrossRef]

14. Toida, J.; Kondoh, K.; Fukuzawa, M.; Ohnishi, K.; Sekiguchi, J. Purification and characterization of a lipase from Aspergillus oryzae. Biosci. Biotechnol. Biochem. 1995, 59, 1199-1203. [CrossRef] [PubMed] 
15. Colla, L.M.; Ficanha, A.M.M.; Rizzardi, J.; Bertolin, T.E.; Reinehr, C.O.; Costa, J.A.V. Production and characterization of lipases by two new isolates of Aspergillus through solid-state and submerged fermentation. BioMed Res. Int. 2015. [CrossRef] [PubMed]

16. Ohnishi, K.; Yoshida, Y.; Toita, J.; Sekiguchi, J. Purification and characterization of a novel lipolytic enzyme from Aspergillus oryzae. J. Ferment. Bioeng. 1994, 78, 413-419. [CrossRef]

17. Svendsen, A. Lipase protein engineering. Biochim. Biophys. Acta (BBA) Protein Struct. Mol. Enzymol. 2000, 1543, 223-238. [CrossRef]

18. Fox, P.F.; McSweeney, P.L.H. Dairy Chemistry and Biochemistry; Springer: Berlin, Germany, 1998.

19. Gerez, C.L.; Torres, M.J.; Font de Valdez, G.; Rollán, G. Control of spoilage fungi by lactic acid bacteria. Biol. Control 2013, 64, 231-237. [CrossRef]

20. Muhialdin, B.J.; Hassan, Z. Screening of Lactic Acid Bacteria for Antifungal Activity against Aspergillus oryzae. Am. J. Appl. Sci. 2011, 8, 447-451. [CrossRef]

21. Torres, A.; Li, S.M.; Roussos, S.; Vert, M. Screening of microorganisms for biodegradation of poly (lactic-acid) and lactic acid-containing polymers. Appl. Environ. Microbiol. 1996, 62, 2393-2397. [PubMed]

22. Torres, A.; Li, S.M.; Roussos, S.; Vert, M. Degradation of L- and DL-lactic acid oligomers in the presence ofFusarium moniliforme andPseudomonas putida. J. Environ. Polym. Degrad. 1996, 4, 213-223. [CrossRef]

23. De Vrese, M.; Laue, C.; Offick, B.; Soeth, E.; Repenning, F.; Thoß, A.; Schrezenmeir, J. A combination of acid lactase from Aspergillus oryzae and yogurt bacteria improves lactose digestion in lactose maldigesters synergistically: A randomized, controlled, double-blind cross-over trial. Clin. Nutr. 2014, 34, 394-399. [CrossRef] [PubMed]

(c) 2017 by the authors. Licensee MDPI, Basel, Switzerland. This article is an open access article distributed under the terms and conditions of the Creative Commons Attribution (CC BY) license (http://creativecommons.org/licenses/by/4.0/). 